\title{
Influence of Mixed Valence on the Formation of Oxygen Vacancy in Cerium Oxides
}

\author{
Gege Zhou ${ }^{1,2}$, Wentong Geng ${ }^{2}$, Lu Sun ${ }^{1}$, Xue Wang ${ }^{1}$, Wei Xiao ${ }^{1}$, Jianwei Wang ${ }^{1}(\mathbb{C}$ and \\ Ligen Wang ${ }^{1, *}$
}

1 General Research Institute for Nonferrous Metals, Materials Computation Center, GRIMAT Engineering Institute Co. Ltd., Beijing 100088, China; zgg8997@126.com (G.Z.); sunlu@grinm.com (L.S.); wangxue@grinm.com (X.W.); xiaowei@grinm.com (W.X.); wangjianwei@grinm.com (J.W.)

2 School of Materials Science and Engineering, University of Science and Technology Beijing, Beijing 100083, China; geng@mater.ustb.edu.cn

* Correspondence: lg_wang1@yahoo.com; Tel.: +86-10-6066-2753

Received: 6 November 2019; Accepted: 25 November 2019; Published: 5 December 2019

check for updates

\begin{abstract}
Ceria is one of the most important functional rare-earth oxides with wide industrial applications. Its amazing oxygen storage/release capacity is attributed to cerium's flexible valence conversion between $4+$ and $3+$. However, there still exists some debate on whether the valence conversion is due to the $\mathrm{Ce}-4 \mathrm{f}$ electron localization-delocalization transition or the character of $\mathrm{Ce}-\mathrm{O}$ covalent bonds. In this work, a mixed valence model was established and the formation energies of oxygen vacancies and electronic charges were obtained by density functional theory calculations. Our results show that the formation energy of oxygen vacancy is affected by the valence state of its neighboring Ce atom and two oxygen vacancies around a $\mathrm{Ce}^{4+}$ in $\mathrm{CeO}_{2}$ have a similar effect to a $\mathrm{Ce}^{3+}$. The electronic charge difference between $\mathrm{Ce}^{3+}$ and $\mathrm{Ce}^{4+}$ is only about $0.4 e$. Therefore, we argue that the valence conversion should be understood according to the adjustment of the ratio of covalent bond to ionic bond. We propose that the formation energy of oxygen vacancy be used as a descriptor to determine the valence state of Ce in cerium oxides.
\end{abstract}

Keywords: cerium oxide; electron valence state; first-principles calculation; oxygen vacancy

\section{Introduction}

$\mathrm{CeO}_{2}$ is a widely used material in various important technological fields, such as solid oxide fuel cells [1] and three-way catalysts [2]. It is a remarkable feature that Ce can be flexibly converted between a valence of $4+$ and a valence of $3+$. This leads to the easy generation of oxygen vacancies in the crystal lattice and its high oxygen storage capacity. The Ce valence state change also has a direct and significant influence on its catalytic efficiency. It is still widely debated where the extra two electrons go after an oxygen vacancy is created. Some researchers argued that the two electrons left behind by the oxygen vacancy are localized to two neighboring Ce atoms and the corresponding Ce atoms are reduced to a valence state of 3+ [3]; others claimed that the extra two electrons are localized to four nearby Ce atoms that have a fractional valence state of 3.5+ [4]. There are also arguments about the electron occupancy of Ce-4f orbital in $\mathrm{CeO}_{2}$. While Wuilloud [5] believed that Ce-4f was almost unoccupied and that Ce ions presented a $4+$ valence, Fujimori [6] and Normand et al. [7,8] believed that $\mathrm{Ce}-4 \mathrm{f}$ electrons should be in a 0.5 occupation state so that Ce presented a fractional or intermediate valence state more similar to covalent bonds. Koelling et al. [9] found charge overlaps between Ce and $\mathrm{O}$ and claimed that the bonding mode of $\mathrm{Ce}-\mathrm{O}$ should be a covalent bond. Due to the covalent bonding character, the valence state for Ce must be in the transition zone of $3+\sim 4+$. In fact, $\mathrm{Ce}-\mathrm{O}$ bonding was found to have a visible polarization that is not typical for a pure ionic bonding [10]. The quantum 
theory of atoms in molecules QTAIM analysis [11,12] showed that the electron density and its associated Laplacian could be partitioned into covalent, ionic, and resonance components [13]. The electron-pair bonding is usually a continuous spectrum of intermediate situations stretching between the covalent and ionic extremes [13]. Therefore, the argument about the Ce valence in the transition zone of 3+ $4+$, based on the covalent bonding character, is plausible. For the Ce valence state, the following four scenarios may exist: (1) Ce has a valence of $4+$ in $\mathrm{CeO}_{2} ;(2)$ the $\mathrm{Ce}$ valence state is reduced within the range of $3+\sim 4+$ when few oxygen vacancies or n-type dopants exist in cerium oxides; (3) Ce cations have two valence states of $3+$ and $4+$, i.e., a mixed valence model, when there are multiple oxygen vacancies in a local area of $\mathrm{CeO}_{2}$ to completely reduce some $\mathrm{Ce}$ to the $3+$ valence $\mathrm{Ce}$; (4) in $\mathrm{Ce}_{2} \mathrm{O}_{3}$, the Ce atoms are a complete valence of $3+$. When $\mathrm{Ce}$ is in the region of the $3+\sim 4+$ valence state, it is generally accepted that oxygen vacancy has an effect on the change of its valence state. But to what extent do oxygen vacancies affect the Ce valence state? If there is a pre-existing $3+\mathrm{Ce}$, how will it affect the formation of oxygen vacancies? The answers to these questions are unclear. To date, how the $\mathrm{Ce}$ valence state responds to the continuous generation of oxygen vacancies remains largely unknown.

We know that it is harder to form an oxygen vacancy in $\mathrm{Ce}_{2} \mathrm{O}_{3}$ than in $\mathrm{CeO}_{2}$ because in $\mathrm{Ce}_{2} \mathrm{O}_{3}$ the $\mathrm{Ce}$ atoms are in the reduced state. When a $\mathrm{Ce}$ atom changes its valence state from $4+$ to $3+$, making itself similar to $\mathrm{Ce}^{3+}$ in $\mathrm{Ce}_{2} \mathrm{O}_{3}$, it will become more difficult to form an oxygen vacancy around this $\mathrm{Ce}$ atom. On the other hand, if oxygen vacancies are continuously introduced around a 4+ Ce in $\mathrm{CeO}_{2}$, the formation of oxygen vacancy will also become more and more difficult. At a point, the formation energy of oxygen vacancy around a $\mathrm{Ce}^{4+}$ in $\mathrm{CeO}_{2}$ reaches the formation energy of oxygen vacancy in $\mathrm{Ce}_{2} \mathrm{O}_{3}$. At this point, we can consider the $\mathrm{Ce}$ atom to have completely changed its valence state from $4+$ to $3+$. In this paper, we propose to use the formation energy of oxygen vacancy as a descriptor or prober to detect the valence state of Ce in cerium oxides. In order to do so, we built a mixed valence model following Takenori Yamamoto et al. [14] and calculated the formation energy of oxygen vacancy in the mixed valence supercell. Although the formation energy of oxygen vacancy is larger when it is closer to $\mathrm{Ce}^{3+}$ than to $\mathrm{Ce}^{4+}$, the results show that they all are lower than that of $\mathrm{Ce}_{2} \mathrm{O}_{3}$. This may be understood according to the features of $\mathrm{Ce}-\mathrm{O}$ covalent bonds and the adjustment of the ratio of covalent bond to ionic bond.

\section{Computational Method}

The calculations were performed within the framework of density functional theory as implemented in the Vienna ab initio simulation package (VASP.5.4.4, University of Vienna, Wien, Austria) [15]. The electron-ion interaction was described using the projector augmented wave (PAW) method [16] with valence $5 s^{2} 5 p^{6} 5 d^{1} 4 f^{1} 6 s^{2}$ for Ce and $2 s^{2} 2 p^{4}$ for the $O$ atom and the electron exchange and correlation were treated within the generalized gradient approximation (GGA) in the Perdew-Burke-Ernzerhof (PBE) [17] form. The cut-off energy for the basis set was set to $500 \mathrm{eV}$ for all the systems. In order to account for the strong on-site Coulomb repulsion among the Ce $4 \mathrm{f}$ electrons, a Hubbard parameter $U$ was also included and $U$ was set as $5 \mathrm{eV}[18,19]$. The supercells (see Supplementary Material) employed in our calculations are shown in Figure 1. The supercells employed for $\mathrm{CeO}_{2}$ and $\mathrm{Ce}_{2} \mathrm{O}_{3}$ calculations are relatively small but they have similar lateral dimensions to those in the mixed valence model. The $16 \times 16 \times 16,16 \times 16 \times 8$ and $16 \times 16 \times 4$ Monkhorst-Pack k-meshes were used for the Brillouin zone sampling for $\mathrm{CeO}_{2}, \mathrm{Ce}_{2} \mathrm{O}_{3}$, and the mixed valence system, respectively. The atomic positions and cell parameters were allowed to relax in the calculations until the forces on all atoms were smaller than $0.01 \mathrm{eV} / \AA$, and the total energies were converged to $10^{-5} \mathrm{eV}$. We performed non-spin polarized calculations for these systems. The optimized structure parameters are listed in Table 1, together with the experimental and other theoretical values [14,20-25] for comparison. It can be seen that the calculated lattice parameters of $\mathrm{CeO}_{2}$ and $\mathrm{Ce}_{2} \mathrm{O}_{3}$ are consistent with the experimental values. For the mixed valence model, we obtained $\mathrm{a}=3.826$ and $\mathrm{c}=15.546$, which are comparable to 3.822 and 15.351 by Yamamoto et al. [14]. 


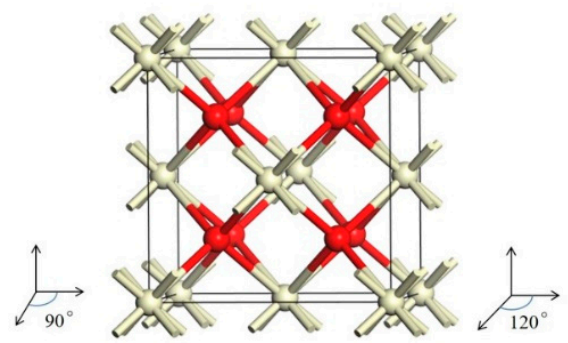

(a)

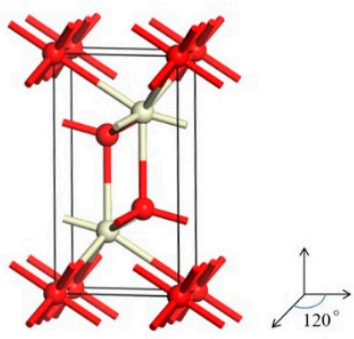

(b)

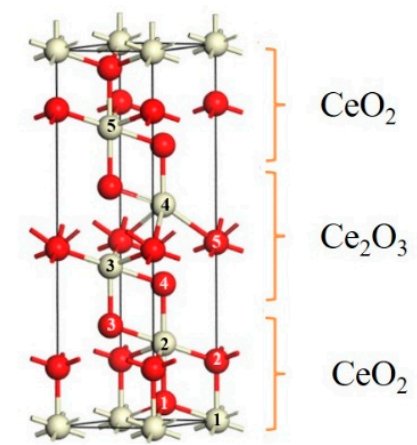

(c)

Figure 1. (a) Fluorite-type structure of $\mathrm{CeO}_{2}$. (b) Hexagonal A-type structure of $\mathrm{Ce}_{2} \mathrm{O}_{3}$. (c) $\mathrm{CeO}_{2} / \mathrm{Ce}_{2} \mathrm{O}_{3}$ mixed valence structure model. $\mathrm{Ce}$ atoms are represented by large grey spheres, and $\mathrm{O}$ atoms by small red spheres.

Table 1. Our calculated equilibrium lattice parameters (in $\AA$ ), together with the experimental and other theoretical values $[14,20-25]$ listed for comparison.

\begin{tabular}{ccccc}
\hline & & This Work & Experiment & Theory \\
\hline $\mathrm{CeO}_{2}$ & $\mathrm{a}$ & 5.48 & $5.41[20]$ & $5.48[21] 5.43[22]$ \\
$\mathrm{h}-\mathrm{Ce}_{2} \mathrm{O}_{3}$ & $\mathrm{a}$ & 3.89 & $3.89[23]$ & $3.94[24] 3.92[25]$ \\
& $\mathrm{c}$ & 6.18 & $6.07[23]$ & $6.19[24] 6.18[25]$ \\
$\mathrm{CeO}_{2} / \mathrm{Ce}_{2} \mathrm{O}_{3}$ & $\mathrm{a}$ & 3.826 & & $3.822[14]$ \\
& $\mathrm{c}$ & 15.546 & & $15.351[14]$ \\
\hline
\end{tabular}

\section{Results and Discussion}

The formation energy of an oxygen vacancy is calculated by

$$
E_{f}^{V_{o}}=\mathrm{E}^{\mathrm{tot}}\left(V_{o}\right)-\mathrm{E}^{\mathrm{tot}}(\mathrm{ref})+\frac{1}{2} \mathrm{E}\left(\mathrm{O}_{2}\right)
$$

where $\mathrm{E}^{\text {tot }}$ (ref) is the total energy of the reference system, and $\mathrm{E}^{\text {tot }}\left(V_{o}\right)$ is the total energy of the supercell that is established by removing one oxygen atom from the reference system. The reference system may have included oxygen vacancies. $\mathrm{E}\left(\mathrm{O}_{2}\right)$ is the total energy for the ground state of an optimized oxygen molecule in the gas phase.

According to Equation (1), we obtain the formation energy of an oxygen vacancy in $\mathrm{CeO}_{2}$ to be $+4.48 \mathrm{eV}$, which is in agreement with the experiment values of +4.68 [26] and $4.2 \pm 0.3 \mathrm{eV}$ [27] . The theoretical results obtained by DFT (Density Functional Theory) calculations vary in the large range of 2.84 6.74 eV [27]. There are two kinds of oxygen sites in cerium trioxide. The calculated oxygen vacancy formation energies are $5.4 \mathrm{eV}$ and $5.7 \mathrm{eV}$, respectively. The lower oxygen vacancy formation energy of $5.4 \mathrm{eV}$ was selected in the following discussions. Our calculated results are consistent with the non-reducible character of $\mathrm{Ce}_{2} \mathrm{O}_{3}$, requiring the large energy $(>5.0 \mathrm{eV})$ to form an oxygen vacancy [24]. In the mixed valence state model, there exist five possible inequivalent oxygen-vacancy sites, as shown in Figure 1. The calculated formation energies for these oxygen vacancies are given in Table 2 and Figure 2. Among the five possible sites, the oxygen vacancy $\mathbf{V}_{\mathrm{O} 1}$ has the lowest formation energy of $4.79 \mathrm{eV}$. By comparing the formation energies of oxygen vacancy at five different sites in the mixed valence state, the formation energies of $\mathbf{V}_{\mathrm{O} 4}$ and $\mathbf{V}_{\mathrm{O} 5}$ are the most positive, reaching $5.32 \mathrm{eV}$, which is about $0.5 \mathrm{eV}$ higher than that for $\mathbf{V}_{\mathrm{O} 1}$. This is because there is a $\mathrm{Ce}^{3+}$ atom near sites 4 and 5 , and it is more difficult to form an oxygen vacancy around a $\mathrm{Ce}^{3+}$ than around a Ce ${ }^{4+}$. In Table 2, the oxygen vacancy formation energies around a $\mathrm{Ce}^{4+}$ in $\mathrm{CeO}_{2}$ are also given. We can see that the oxygen vacancy formation becomes increasingly more difficult when oxygen vacancies around the Ce atom already exist. It is worth noting that the formation energies of the first two oxygen vacancies are 
smaller than the formation energy of an oxygen vacancy in $\mathrm{Ce}_{2} \mathrm{O}_{3}$ and those for $\mathbf{V}_{\mathrm{O} 4}$ and $\mathbf{V}_{\mathrm{O} 5}$ in the mixed valence state model. However, the formation energy of the third oxygen vacancy around a $\mathrm{Ce}^{4+}$ in $\mathrm{CeO}_{2}$ is larger than that in $\mathrm{Ce}_{2} \mathrm{O}_{3}$. In other words, it is more difficult to generate the third oxygen vacancy around a $\mathrm{Ce}$ atom in $\mathrm{CeO}_{2}$ than to generate an oxygen vacancy in $\mathrm{Ce}_{2} \mathrm{O}_{3}$. This means that the presence of the $3+$ cerium has a larger effect than that of one oxygen vacancy and a similar effect of two oxygen vacancies around a $\mathrm{Ce}^{4+}$ in $\mathrm{CeO}_{2}$. We may also argue that it might not result in two $\mathrm{Ce}^{3+}$ when one oxygen vacancy is generated in $\mathrm{CeO}_{2}$. The $\mathrm{Ce}$ valence state is more likely to be between $3+$ and $4+$. This argument is consistent with the existence of covalent bonds in cerium dioxides.

Table 2. Oxygen vacancy formation energies for various oxygen locations in the mixed valence state model and around a $\mathrm{Ce}$ atom in $\mathrm{CeO}_{2}$.

\begin{tabular}{cccccc}
\hline $\mathrm{CeO}_{2} / \mathrm{Ce}_{2} \mathbf{O}_{3}$ & $\mathbf{V}_{\mathbf{O} 1}$ & $\mathbf{V}_{\mathbf{O} 2}$ & $\mathbf{V}_{\mathbf{O} 3}$ & $\mathbf{V}_{\mathbf{O} 4}$ & $\mathbf{V}_{\mathbf{O} 5}$ \\
\hline $\mathrm{E}_{\mathrm{f}}(\mathrm{eV})$ & 4.79 & 4.91 & 5.25 & 5.27 & 5.32 \\
\hline $\mathrm{CeO}_{2}$ & $\mathrm{~V}_{\mathrm{O}}^{1 s t}$ & $\mathrm{~V}_{\mathrm{O}}^{2 n d}$ & $\mathrm{~V}_{\mathrm{O}}^{3 \text { rd }}$ & $\mathrm{V}_{\mathrm{O}}^{4 t h}$ & \\
\hline $\mathrm{E}_{\mathrm{f}}(\mathrm{eV})$ & 4.49 & 5.17 & 5.57 & 5.82 & \\
\hline
\end{tabular}

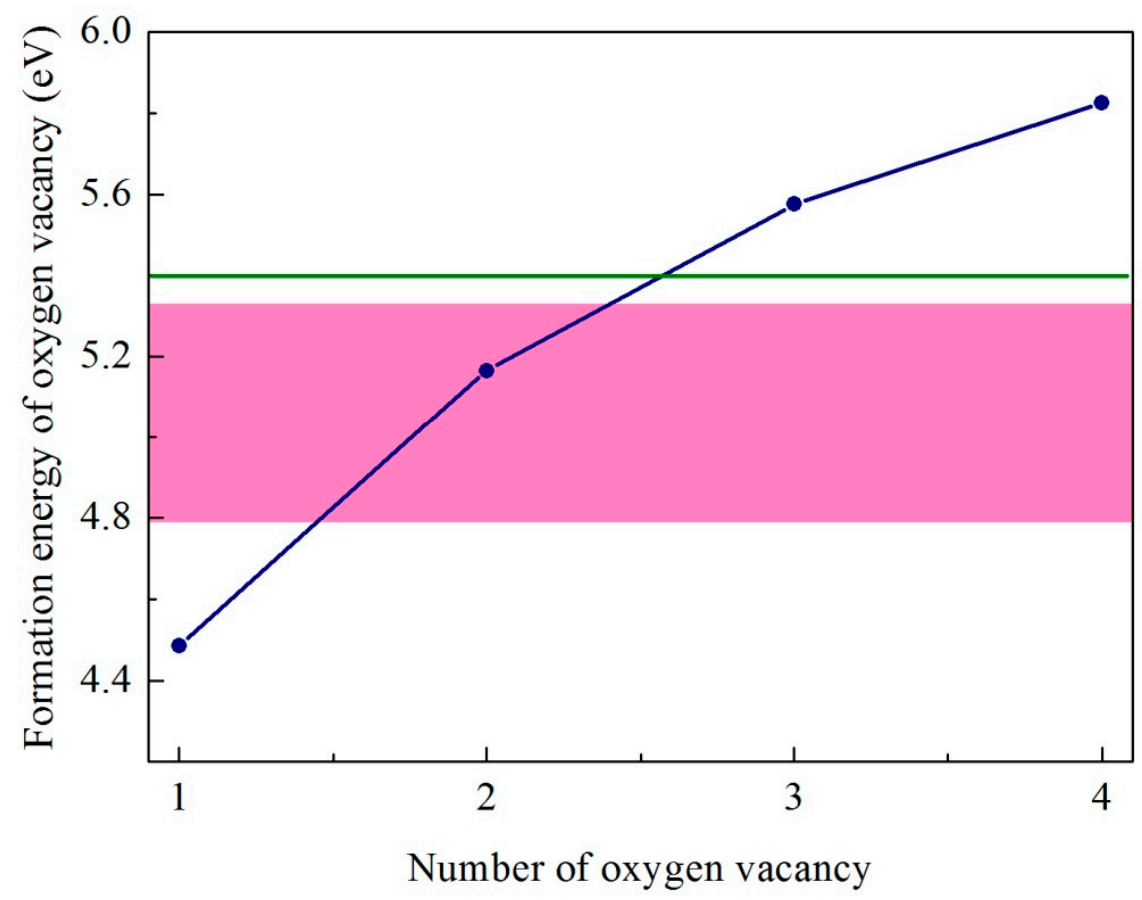

Figure 2. The calculated formation energy of oxygen vacancy as a function of the number of total oxygen vacancies around a $\mathrm{Ce}$ atom in $\mathrm{CeO}_{2}$. The shaded region represents the range of oxygen vacancy formation energy in the mixed valence structure. The horizontal line represents the formation energy of oxygen vacancy in $\mathrm{Ce}_{2} \mathrm{O}_{3}$.

Bader's charge analysis was used to obtain the total electronic charges of the atoms in $\mathrm{CeO}_{2}$, $\mathrm{Ce}_{2} \mathrm{O}_{3}$, and the mixed valence system. The results are presented in Table 3. We can see that in the mixed valence model, the oxygen and cerium atoms in the $\mathrm{Ce}_{2} \mathrm{O}_{3}$ region have higher electronic charges compared to those in the $\mathrm{CeO}_{2}$ region. For $\mathrm{Ce} 3$ and $\mathrm{Ce} 4$, they have about 0.4 more electrons than other $\mathrm{Ce}$ atoms in the mixed valence model. Except for $\mathrm{Ce} 3$ and $\mathrm{Ce} 4$, the other $\mathrm{Ce}$ atoms in the supercell have charges close to those $\mathrm{Ce}$ atoms in $\mathrm{CeO}_{2}$ bulk. This implies that $\mathrm{Ce} 1, \mathrm{Ce} 2$, and $\mathrm{Ce} 5$ have an environment similar to $\mathrm{CeO}_{2}$. We normally consider $\mathrm{Ce}$ to have a valence of $4+$ in $\mathrm{CeO}_{2}$ and $3+$ in $\mathrm{Ce}_{2} \mathrm{O}_{3}$. However, the Bader charge difference between $3+\mathrm{Ce}$ and $4+\mathrm{Ce}$ is only about $0.4 e$. Therefore, it is believed that the valence state adjustment is actually achieved by adjusting the ratio of covalent bond to ionic bond. This notion that cerium oxides have the features of covalent bonds is 
consistent with previous studies [9]. The charge density distribution of cerium dioxide is plotted in Figure 3. It shows a charge bridge between the Ce and oxygen centers [9]. Therefore, it was considered to form covalent bonds between the Ce and oxygen centers [9]. However, because the electronegativity difference between $\mathrm{Ce}$ and $\mathrm{O}$ is about 2.0 [28], the $\mathrm{Ce}-\mathrm{O}$ bonds should include an ionic bond character. To quantitatively characterize covalent and ionic bonding, a QTAIM analysis [11-13] of the topology of the total density should be performed at the bond critical point.

Table 3. Bader's total charge analysis for $\mathrm{CeO}_{2}, \mathrm{Ce}_{2} \mathrm{O}_{3}$, and the mixed valence structure.

\begin{tabular}{ccc}
\hline System & Atom & Bader Charge \\
\hline $\mathrm{CeO}_{2}$ & $\mathrm{O}$ & 7.19 \\
& $\mathrm{Ce}$ & 9.60 \\
\hline & $\mathrm{O} 1$ & 7.21 \\
& $\mathrm{O} 2$ & 7.22 \\
& $\mathrm{O} 3$ & 7.22 \\
& $\mathrm{O} 4$ & 7.31 \\
$\mathrm{CeO}_{2}-\mathrm{Ce}_{2} \mathrm{O}_{3}$ & $\mathrm{O} 5$ & 7.40 \\
& $\mathrm{Ce} 1$ & 9.56 \\
& $\mathrm{Ce} 2$ & 9.58 \\
& $\mathrm{Ce} 3$ & 9.97 \\
& $\mathrm{Ce} 4$ & 9.99 \\
& $\mathrm{Ce} 5$ & 9.63 \\
\hline & $\mathrm{O} 1$ & 7.39 \\
$\mathrm{Ce}_{2} \mathbf{O}_{3}$ & $\mathrm{O} 2$ & 7.31 \\
& $\mathrm{Ce}$ & 9.99 \\
\hline
\end{tabular}

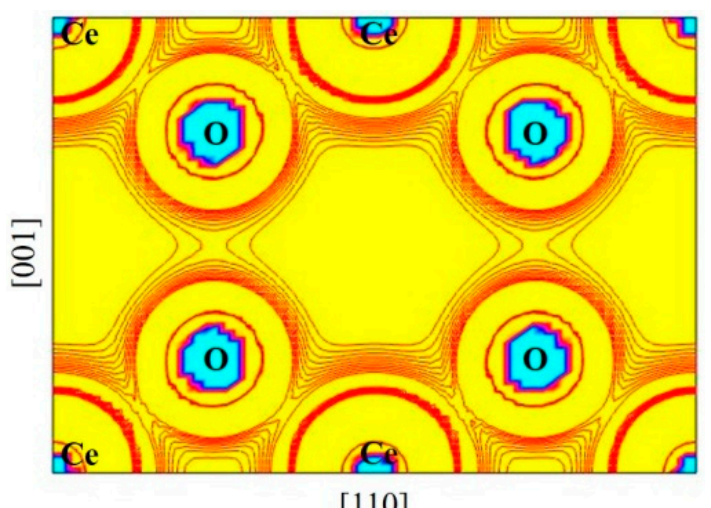

[110]

Figure 3. The valence charge density of the (110) plane for pure cerium dioxide.

The partial densities of states (PDOSs) for $\mathrm{Ce}^{3+}$ and $\mathrm{Ce}^{4+}$ in the mixed valence model and the $\mathrm{Ce}$ atom next to two oxygen vacancies in $\mathrm{CeO}_{2}$ are shown in Figure 4. From this, we can see the following: (1) the $4 \mathrm{f}$ state is unoccupied for $\mathrm{Ce}^{4+}$ in the mixed valence model, while it is partially occupied for $\mathrm{Ce}^{3+}$; (2) the $\mathrm{O} 2 \mathrm{p}-\mathrm{Ce} 4 \mathrm{f}$ gap is larger for $\mathrm{Ce}^{4+}$ than that for $\mathrm{Ce}^{3+}$. Our previous study [29] indicated that the $4 \mathrm{f}$ state of $\mathrm{Ce}^{3+}$ in $\mathrm{Ce}_{2} \mathrm{O}_{3}$ splits into occupied $\left(4 \mathrm{f}^{1}\right)$ and unoccupied $\left(4 \mathrm{f}^{0}\right)$ states, rendering a $\mathrm{Ce}_{2} \mathrm{O}_{3}$ a Mott insulating phase. In the mixed valence model, while we do not restrict the electron to completely localize at the $\mathrm{Ce}$ atom, the partial occupation of the $\mathrm{Ce}^{3+}-4 \mathrm{f}$ state may be because it is similar to a polaron in $\mathrm{CeO}_{2}$ [30]. Figure $4 \mathrm{c}$ shows that after introducing two oxygen vacancies around a $\mathrm{Ce}^{4+}$ in $\mathrm{CeO}_{2}$, its PDOS is very similar to that of $\mathrm{Ce}^{3+}$ in the mixed valence model, i.e., the $4 \mathrm{f}$ state is partially occupied and the $\mathrm{O} 2 \mathrm{p}-\mathrm{Ce} 4 \mathrm{f}$ gap becomes narrower than that for $\mathrm{Ce}^{4+}$. The multiple peaks in the Ce $4 \mathrm{f}$ state may be attributed to the lattice distortion due to the oxygen vacancies. This also verifies, from another angle, that the valence state change of $\mathrm{Ce}$ is accompanied by generating oxygen vacancies around a Ce atom. 


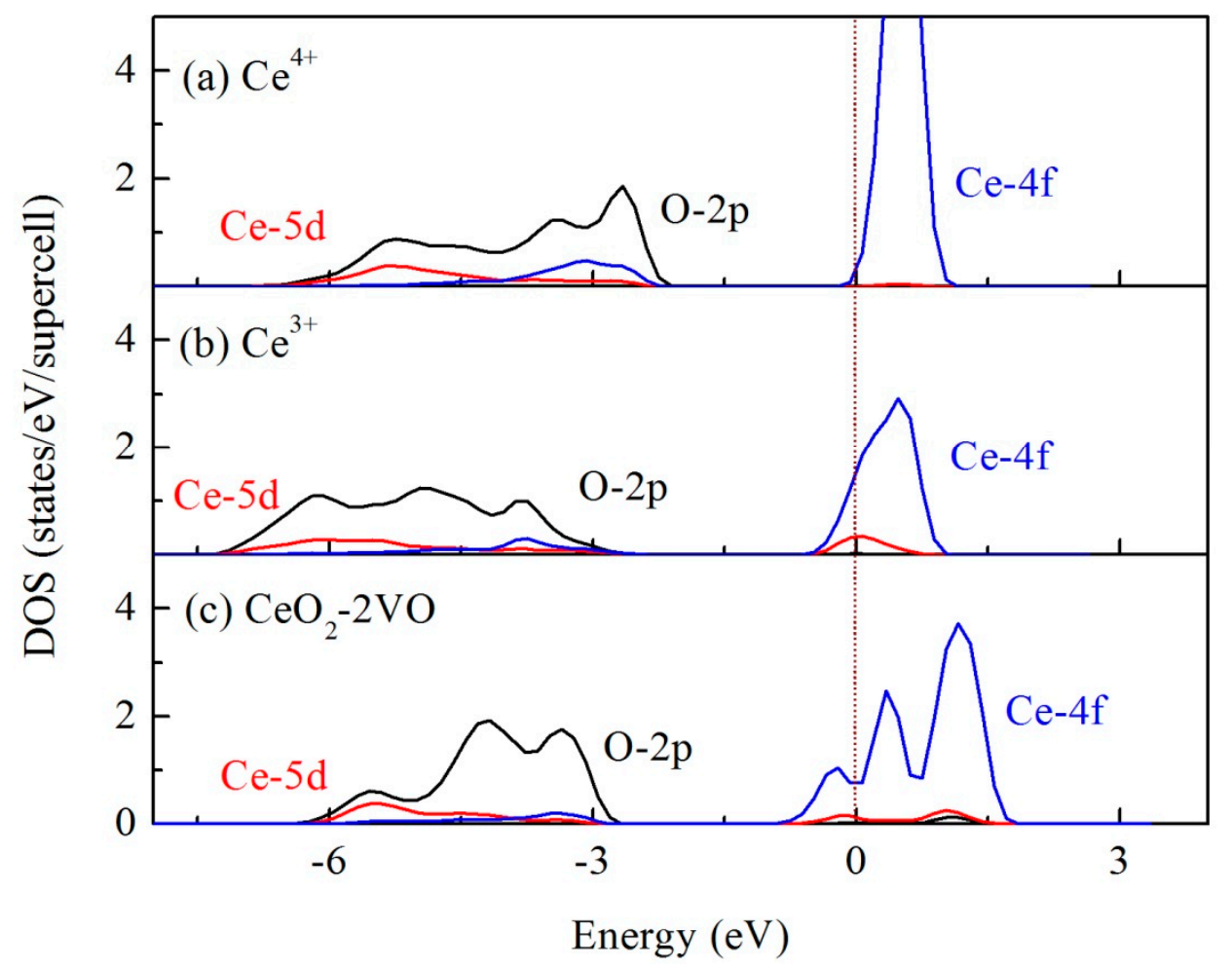

Figure 4. Partial densities of states (PDOS) state density distribution of mixed valence state model: the black, red, and blue lines represent the $\mathrm{O}-2 \mathrm{p}, \mathrm{Ce}-5 \mathrm{~d}$, and $4 \mathrm{f}$ orbital electrons, respectively. The dotted line represents the Fermi level: (a) $\mathrm{Ce}^{4+}$ in mixed valence model (b) $\mathrm{Ce}^{3+}$ in mixed valence model (c) Ce nearest to two oxygen vacancies in pure ceria.

\section{Conclusions}

In this paper, the valence states in cerium oxides were investigated by performing density functional theory calculations based on a mixed valence model. The formation energies of oxygen vacancies and the electronic charges in the mixed valence model were calculated. We found that the formation energy of oxygen vacancy is affected by the valence state of its neighboring Ce atom, and propose that the formation energy of oxygen vacancy can be used as a descriptor to determine the valence state of $\mathrm{Ce}$ in cerium oxides. Our results show that two oxygen vacancies around a $\mathrm{Ce}^{4+}$ in $\mathrm{CeO}_{2}$ have a similar effect to a $\mathrm{Ce}^{3+}$. This is also supported by the partial densities of states that, for both cases, the $4 \mathrm{f}$ state is partially occupied and the $\mathrm{O} 2 \mathrm{p}$-Ce $4 \mathrm{f}$ gap becomes narrower than that for $\mathrm{Ce}^{4+}$. The calculated results further show that the electronic charge difference between $\mathrm{Ce}^{3+}$ and $\mathrm{Ce}^{4+}$ is only about $0.4 e$, far from the nominal charge difference of $1.0 e$. Therefore, the valence state conversion should be understood according to the characters of $\mathrm{Ce}-\mathrm{O}$ covalent bonds and the adjustment of the ratio of covalent bond to ionic bond.

Supplementary Materials: The following are available online at http://www.mdpi.com/1996-1944/12/24/4041/s1, Table S1: POSCAR for $\mathrm{CeO}_{2}$ (Figure 1a), Table S2: POSCAR for $\mathrm{Ce}_{2} \mathrm{O}_{3}$ (Figure 1b), Table S3: POSCAR for $\mathrm{CeO}_{2}$ $-\mathrm{Ce}_{2} \mathrm{O}_{3}$ (Figure 1c).

Author Contributions: Conceptualization, G.Z. and L.W.; Funding acquisition, W.X., L.S., L.W. and J.W.; Investigation, G.Z., X.W., L.S. and W.X.; Supervision, W.G., J.W. and L.W.; Writing-original draft, G.Z.; Writing-review \& editing, W.G. and L.W.

Funding: This work was funded by the National Key R\&D Program of China (No. 2016YFB0700704), the National Natural Science Foundation of China (Grant Nos. 11804293 and 11704041).

Conflicts of Interest: The authors declare no conflict of interest. 


\section{References}

1. Kharton, V.V.; Figueiredo, F.M.; Navarro, L.; Naumovich, E.N.; Kovalevsky, A.V.; Yaremchenko, A.A.; Viskup, A.P.; Carneiro, A.; Marques, F.M.B.; Frade, J.R. Ceria-based materials for solid oxide fuel cells. J. Mater. Sci. 2001, 36, 1105-1117. [CrossRef]

2. Kašpar, J.; Fornasiero, P.; Graziani, M. Use of $\mathrm{CeO}_{2}$-based oxides in the three-way catalysis. Catal. Today 1999, 50, 285-298. [CrossRef]

3. Skorodumova, N.V.; Simak, S.I.; Lundqvist, B.I.; Abrikosov, I.A.; Johansson, B. Quantum origin of the oxygen storage capability of ceria. Phys. Rev. Lett. 2002, 89, 166601. [CrossRef] [PubMed]

4. Jiang, Y.; Adams, J.B.; Schilfgaarde, M.V. Theoretical study of environmental dependence of oxygen vacancy formation in $\mathrm{CeO}_{2}$. Appl. Phys. Lett. 2005, 87, 141915. [CrossRef]

5. Wuilloud, E.; Delley, B.; Schneider, W.D.; Baer, Y. Spectroscopic evidence for localized and extended f-symmetry states in $\mathrm{CeO}_{2}$. Phys. Rev. Lett. 1984, 53, 202-205. [CrossRef]

6. Fujimori, A. $4 f$ - and core-level photoemission satellites in cerium compounds. Phys. Rev. B 1983, 27, 3992-4001. [CrossRef]

7. Le Normand, F.; El Fallah, J.; Hilaire, L.; Legare, P.; Kotani, A.; Parlebas, J.C. Photoemission on 3d core levels of cerium: An experimental and theoretical investigation of the reduction of the cerium dioxide. Solid State Commun. 1989, 71, 885-889. [CrossRef]

8. Marabelli, F.; Wachter, P. Covalent insulator $\mathrm{CeO}_{2}$ : Optical reflectivity measurements. Phys. Rev. B 1987, 36, 1238-1243. [CrossRef]

9. Koelling, D.D.; Boring, A.M.; Wood, J.H. The electronic structure of $\mathrm{CeO}_{2}$ and $\mathrm{PrO}_{2}$. Solid State Commun. 1983, 47, 227-232. [CrossRef]

10. Skorodumova, N.V.; Ahuja, R.; Simak, S.I.; Abrikosov, A.; Johansson, B.; Lundqvist, B.I. Electronic, bonding, and optical properties of $\mathrm{CeO}_{2}$ and $\mathrm{Ce}_{2} \mathrm{O}_{3}$ from first principles. Phys. Rev. B 2001, 64, 115108. [CrossRef]

11. Bader, R.F.W. Atoms in Molecules: A Quantum Theory; Oxford University Press: Oxford, UK, 1990.

12. Bader, R.F.W. A quantum theory of molecular structure and its applications. Chem. Rev. 1991, 91, 893-928. [CrossRef]

13. Zhang, L.; Ying, F.; Wu, W.; Hiberty, P.C.; Shaik, S. Topology of electron charge density for chemical bonds from valence bond theory: A probe of bonding types. Chem. Eur. J. 2009, 15, 2979-2989. [CrossRef] [PubMed]

14. Yamamoto, T.; Momida, H.; Hamada, T.; Uda, T.; Ohno, T. First-principles study of dielectric properties of cerium oxide. Thin Solid Films 2005, 486, 136-140. [CrossRef]

15. Kresse, G.; Furthmuller, J. Efficient iterative schemes for ab initio total-energy calculations using a plane-wave basis set. Phys. Rev. B 1996, 54, 11169-11173. [CrossRef] [PubMed]

16. Kresse, G.; Joubert, D. From ultra-soft pseudo-potentials to the projector augmented-Wave method. Phys. Rev. B 1999, 59, 1758-1762. [CrossRef]

17. Perdew, J.P.; Burke, K.; Ernzerhof, M. Generalized gradient approximation made simple. Phys. Rev. Lett. 1996, 77, 3865-3868. [CrossRef]

18. Ma, D.W.; Lu, Z.S.; Tang, Y.N.; Li, T.X.; Tang, Z.J.; Yang, Z.X. Effect of lattice strain on the oxygen vacancy formation and hydrogen adsorption at $\mathrm{CeO}_{2}$ (111) surface. Phys. Lett. A 2014, 378, 2570-2575. [CrossRef]

19. Aidhy, S.D.; Liu, B.; Zhang, Y.W.; Weber, W.J. Chemical expansion affected oxygen vacancy stability in different oxide structures from first principles calculations. Comput. Mater. Sci. 2015, 99, 298-305. [CrossRef]

20. Gerward, L.; Staun Olsen, J.; Petit, L.; Vaitheeswaran, G.; Kanchana, V.; Svane, A. Bulk modulus of $\mathrm{CeO}_{2}$ and $\mathrm{PrO}_{2}$-An experimental and theoretical study. J. Alloy. Compd. 2005, 400, 56-61. [CrossRef]

21. Sun, L.; Huang, X.W.; Wang, L.G.; Janotti, A. Disentangling the role of small polarons and oxygen vacancies in $\mathrm{CeO}_{2}$. Phys. Rev. B 2017, 95, 245101-245106. [CrossRef]

22. Kanchana, V.; Vaitheeswaran, G.; Svane, A.; Delin, A. First-principles study of elastic properties of $\mathrm{CeO}_{2}$ $\mathrm{ThO}_{2}$ and $\mathrm{PoO}_{2}$. J. Phys. Condens. Matter 2006, 18, 9615-9624. [CrossRef]

23. Pinto, H.; Mintz, M.H.; Melamud, M.; Shaked, H. Neutron diffraction study of $\mathrm{Ce}_{2} \mathrm{O}_{3}$. Phys. Lett. A 1982, 88, 81-83. [CrossRef]

24. Matz, O.; Calatayud, M. $\mathrm{H}_{2}$ Dissociation and oxygen vacancy formation on $\mathrm{Ce}_{2} \mathrm{O}_{3}$ surfaces. Top. Catal. 2019, 62, 956-967. [CrossRef]

25. Da Silva, J.L.F. Stability of the $\mathrm{Ce}_{2} \mathrm{O}_{3}$ phases: A DFT + U investigation. Phys. Rev. B 2007, 76, 193108-193115. [CrossRef] 
26. Panhans, M.A.; Blumenthal, R.N. A thermodynamic and electrical conductivity study of nonstoichiometric cerium dioxide. Solid State Ionics 1993, 60, 279-298. [CrossRef]

27. Paier, J.; Penschke, C.; Sauer, J. Oxygen defects and surface chemistry of ceria: Quantum chemical studies compared to experiment. Chem. Rev. 2013, 113, 3949-3985. [CrossRef]

28. Li, K.Y.; Xue, D.F. Estimation of electronegativity values of elements in different valence states. J. Phys. Chem. A 2006, 110, 11332-11337. [CrossRef] [PubMed]

29. Sun, L.; Xiao, W.; Hao, X.M.; Meng, Q.L.; Zhou, M. A first-principles study on the structural, thermal and electronic properties of cerium oxides by using different functionals. Electron. Struct. 2019, 1, 015003. [CrossRef]

30. Sun, L.; Hao, X.; Meng, Q.; Wang, L.G.; Liu, F.; Zhou, M. Polaronic resistive switching in ceria-based memory devices. Adv. Electron. Mater. 2019, 5, 1900271. [CrossRef]

(C) 2019 by the authors. Licensee MDPI, Basel, Switzerland. This article is an open access article distributed under the terms and conditions of the Creative Commons Attribution (CC BY) license (http://creativecommons.org/licenses/by/4.0/). 